\title{
Transanal minimally invasive surgery after incomplete resection of a rectal polyp using a full-thickness resection device
}

There are many alternatives for minimally invasive treatment of early colorectal lesions in the rectum. Endoscopic approaches include endoscopic mucosal resection (EMR), endoscopic submucosal resection (ESR), or endoscopic full-thickness resection (eFTR) using the full-thickness resection device (FTRD; Ovesco), which is an alternative after incomplete endoscopic resection, in high risk patients, and for lesions with difficult endoscopic access [1]. Minimally invasive surgical alternatives, such as transanal endoscopic microsurgery (TEM) and transanal minimally invasive surgery (TAMIS), are also available $[2,3]$.

We present the case of a 72-year-old woman under investigation by the gastroenterologist for gastrointestinal disorders. A colonoscopy was performed, which revealed a non-invasive adenomatous lesion, in the form of a laterally spreading tumor (LST) type Ila + Is, arising from the anterior rectal wall, $8 \mathrm{~cm}$ from the anal verge, and occupying $60 \%$ of the lumen. Mucosectomy with piecemeal resection was carried out, with pathological examination of the specimen reporting high grade dysplasia.

A new colonoscopy was performed and a fibrotic lesion was resected using the FTRD ( $\triangleright$ Fig. 1 a), revealing a tubulovillous adenoma with low grade dysplasia. Further endoscopic follow-up showed the metal device (FTRD clip) located on the anterior middle rectal wall and covered with adenomatous tissue ( $\triangleright$ Fig. $1 \mathbf{b})$. A biopsy was taken and the report showed a tubulovillous adenoma with high grade dysplasia.

The patient was discussed with the surgical team, and TAMIS was performed ( $\vee$ Video 1 ), with the free margins being marked ( $\triangleright$ Fig. 2 a), before full-thickness rectal wall resection ( $\downarrow$ Fig. $\mathbf{2} \mathbf{b}$ ), followed by closure of the defect.

Pathological analysis showed a $3.5 \times$ $2.3 \times 1.1-\mathrm{cm}$ specimen, containing a $1.5 \times 1.5-\mathrm{cm}$ lesion with a metal device
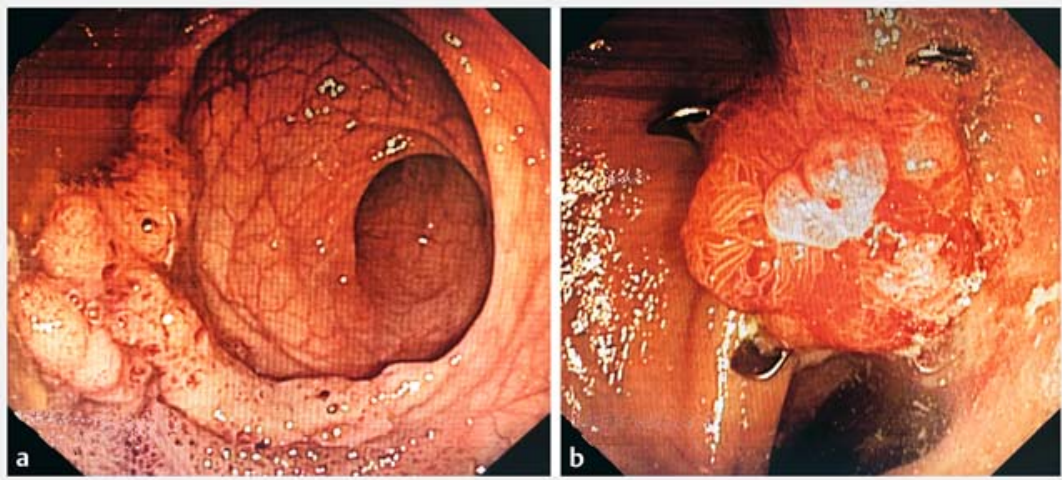

- Fig. 1 Colonoscopic views showing: a a rectal polyp; $\mathbf{b}$ the previously applied full-thickness resection device covered with adenomatous tissue.
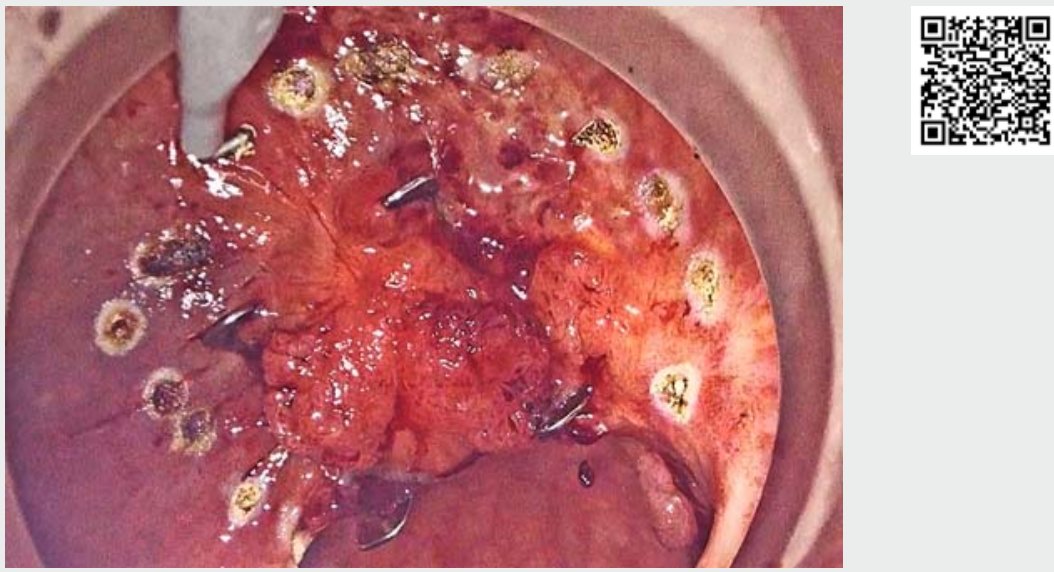

Video 1 Transanal minimally invasive surgery after incomplete resection of a rectal polyp using a full-thickness resection device.
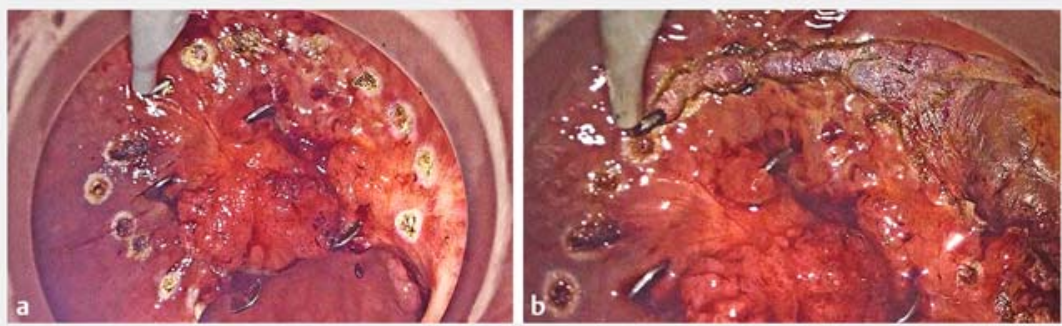

- Fig. 2 Views during transanal minimally invasive surgery (TAMIS) showing: a the free margins being marked; $\mathbf{b}$ full-thickness resection. 
within it. A tubular adenoma with low grade dysplasia and free margins was confirmed.

The patient's postoperative recovery was uneventful and no signs of recurrence were found on follow-up after 6 months. TAMIS is an alternative for failed or incomplete resection after eFTR using the FTRD. It is a safe and feasible technique allowing for a full-thickness rectal resection $[4,5]$.

Endoscopy_UCTN_Code_CPL_1AJ_2AD

\section{Competing interests}

The authors declare that they have no conflict of interest.

The authors

Javier Valdés-Hernández ${ }^{1}$, Auxiliadora Cano', Manuel Rodriguez-Tellez ${ }^{2,3}$, Juan Carlos Gómez-Rosado ${ }^{1}$, Fernando Oliva Mompean ${ }^{1}$

1 Colorectal Surgery Unit, Virgen Macarena University Hospital, Seville, Spain

2 Department of Digestive Diseases, Virgen Macarena University Hospital, Seville, Spain

3 Digestive Endoscopy Unit, Hospital San Agustin, Seville, Spain
Corresponding author

Javier Valdés-Hernandez, MD, PhD

Servicio de Cirugia General y Aparato

Digestivo, Hospital Universitario Virgen

Macarena, Avenida Dr Fedriani s/n. 41009,

Sevilla, Spain

valdeshernandez@hotmail.com

\section{References}

[1] Soriani P, Tontini GE, Neumann $\mathrm{H}$ et al. Endoscopic full-thickness resection for $\mathrm{T} 1$ early rectal cancer: a case series and video report. Endosc Int Open 2017; 5: E1081-E1086

[2] Issa N, Fenig Y, Schmilovitz-Weiss H et al. Simultaneous local excision of synchronous rectal polyps by transanal endoscopic microsurgery. Eur J Gastroenterol Hepatol 2020; 32: $45-47$

[3] Fukami N. Surgery versus endoscopic mucosal resection for large polyps: making sense of when to use which approach. Gastrointest Endosc Clin N Am 2019; 29: 675685

[4] Ono S, Kobayashi R, Ito S et al. A case of successful full-thickness resection using endoscopic submucosal dissection and transanal suturing of rectal cancer. Endoscopy 2019; 51: E301-E302

[5] De Jong GM, Hugen N. Minimally invasive transanal surgery is safe after incomplete polypectomy of low risk $\mathrm{T} 1$ rectal cancer: a systematic review. Colorectal Dis 2019; 21: 1112-1119
Bibliography

Endoscopy 2021; 53: E46-E47

DOI 10.1055/a-1174-6018

ISSN 0013-726X

published online 5.6 .2020

(C) 2020. Thieme. All rights reserved.

Georg Thieme Verlag KG, Rüdigerstraße 14 ,

70469 Stuttgart, Germany

\section{ENDOSCOPY E-VIDEOS}

https://eref.thieme.de/e-videos

回的 Endoscopy E-Videos is a free

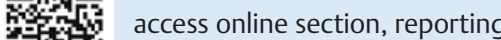
向㶽 on interesting cases and new

techniques in gastroenterological endoscopy. All papers include a high quality video and all contributions are freely accessible online.

This section has its own submission website at https://mc.manuscriptcentral.com/e-videos 